\title{
Patologias do concreto armado e seus métodos de restauração estrutural
}

\author{
Reinforced concrete pathologies and their structural restoration methods \\ Patologías del hormigón armado y sus métodos de restauración estructural
}

Recebido: 17/01/2021 | Revisado: 20/01/2021 | Aceito: 22/01/2021 | Publicado: 30/01/2021

\author{
José Levi Chaves de Sousa \\ ORCID: https://orcid.org/0000-0003-2174-1863 \\ Faculdade Luciano Feijão, Brasil \\ E-mail: levichaves1@hotmail.com \\ Francisco Kelson Melo de Aquino \\ ORCID: https://orcid.org/0000-0001-6634-6002 \\ Faculdade Luciano Feijão, Brasil \\ E-mail: professorkelsonmelo@gmail.com \\ Navilta Veras do Nascimento \\ ORCID: https://orcid.org/0000-0002-2181-4551 \\ Faculdade Luciano Feijão, Brasil \\ E-mail: naviltaveras@gmail.com \\ Antônia Aurileda Vieira da Costa \\ ORCID: https://orcid.org/0000-0003-0907-6901 \\ Faculdade Luciano Feijão, Brasil \\ E-mail: aurileda_vieiraas@hotmail.com \\ José Ciro Sampaio Teixeira \\ ORCID: https://orcid.org/0000-0001-5475-691X \\ Faculdade Luciano Feijão, Brasil \\ E-mail: jcst.12@outlook.com
}

\begin{abstract}
Resumo
As construções baseadas em concreto armado encontram-se como a técnica de construção mais usada em território brasileiro e, nesse sentido, também apresentam uma grande quantidade de patologias, as quais costumam acontecer em várias fases do processo construtivo de uma obra. É necessário, dessa maneira, realizar uma análise adequada acerca das razões mais importantes, bem como agentes causadores, além de planejar métodos preventivos e corretivos. As patologias em concreto armado são capazes de criar danos materiais, financeiros e, inclusive, vitais em caso de vítimas diante de graves problemas na construção - para consumidores, gestores, trabalhadores do campo da engenharia civil, bem como os demais indivíduos envolvidos com a obra. Averiguando-se essa conjuntura, ressalta-se o seguinte problema de pesquisa: quais são os principais métodos de recuperação estrutural em relação às patologias que ocorrem em concreto armado? Referente ao objetivo geral, aferiram-se as propriedades cruciais acerca da patologia em concreto armado. Os objetivos específicos desse estudo são: descrição de aspectos conceituais sobre patologia em concreto armado; caracterização de questões relacionadas sobre a natureza do agravamento estrutural em concreto armado; avaliação de metodologias de recuperação estrutural no concreto armado. Esse estudo foi realizado por meio da metodologia de revisão bibliográfica narrativa (revisão de literatura), baseando-se em obras literárias, em artigos publicados em periódicos offline e também em artigos online reconhecidos no meio científico, onde buscou-se a verificação dos principais métodos de recuperação estrutural em relação às patologias que ocorrem em concreto armado.
\end{abstract}

Palavras-chave: Concreto armado; Construção civil; Engenharia civil; Métodos de recuperação estrutural; Patologia em concreto armado.

\begin{abstract}
Constructions based on reinforced concrete are the most used construction technique in Brazilian territory and, in this sense, they also present a large number of pathologies, which usually happen in several phases of the construction process of a work. It is necessary, therefore, to carry out an adequate analysis of the most important reasons, as well as causative agents, in addition to planning preventive and corrective methods. Reinforced concrete pathologies are capable of creating material, financial and even vital damage - in the case of victims facing serious construction problems - for consumers, managers, civil engineering workers, as well as other individuals involved with constructions. When investigating this situation, the following research problem is highlighted: what are the main methods of structural recovery in relation to the pathologies that occur in reinforced concrete? Regarding the general objective, the crucial properties about the pathology in reinforced concrete were assessed. The specific objectives of this study are: description of conceptual aspects about pathology in reinforced concrete; characterization of related questions about the nature of the structural deterioration in reinforced concrete; evaluation of structural recovery methodologies in reinforced concrete. This study was carried out using the narrative bibliographic review
\end{abstract}


methodology (literature review), based on literary works, articles published in offline journals and also on online articles recognized in the scientific community, where the main methods were checked. of structural recovery in relation to the pathologies that occur in reinforced concrete.

Keywords: Reinforced concrete; Construction; Civil engineering; Structural recovery methods; Reinforced concrete pathology.

\section{Resumen}

Las construcciones a base de hormigón armado son la técnica constructiva más utilizada en territorio brasileño y, en este sentido, también presentan una gran cantidad de patologías, que suelen ocurrir en varias fases del proceso constructivo de una obra. Es necesario, por tanto, realizar un análisis adecuado de las causas más importantes, así como de los agentes causales, además de planificar métodos preventivos y correctivos. Las patologías del hormigón armado son capaces de generar daños materiales, económicos e incluso vitales, en el caso de víctimas que enfrenten serios problemas de construcción, para los consumidores, gerentes, trabajadores de la ingeniería civil y otras personas involucradas con construcciones. Al investigar esta situación, se destaca el siguiente problema de investigación: ¿Cuáles son los principales métodos de recuperación estructural en relación con las patologías que se presentan en el hormigón armado? En cuanto al objetivo general, se evaluaron las propiedades cruciales sobre la patología en el hormigón armado. Los objetivos específicos de este estudio son: descripción de aspectos conceptuales sobre patología en hormigón armado; caracterización de cuestiones relacionadas sobre la naturaleza del deterioro estructural en hormigón armado; evaluación de metodologías de recuperación estructural en hormigón armado. Este estudio se realizó utilizando la metodología de revisión bibliográfica narrativa (revisión de literatura), a partir de trabajos literarios, artículos publicados en revistas offline y también en artículos online reconocidos en la comunidad científica, donde se comprobaron los principales métodos. de recuperación estructural en relación a las patologías que se presentan en el hormigón armado.

Palabras clave: Hormigón armado; Construcción civil; Ingeniería civil; Métodos de recuperación structural; Patología del hormigón armado.

\section{Introdução}

O ramo da construção civil teve seu ritmo de desenvolvimento aumentado em virtude da demanda, cada vez maior, por edificações, para fins laborais, industriais ou habitacionais, junto da respectiva modernização da sociedade tal como se apresenta, o que levou a um evidente avanço científico e tecnológico. Em consequência do crescimento acelerado da construção, diversas estruturas mostraram-se insatisfatórias quanto a seu desempenho, por apresentarem falhas involuntárias, imperícias, utilização inadequada dos materiais escolhidos, desgaste natural ou descuidos no planejamento, por fim existem inúmeros elementos que participam da degradação das estruturas.

A patologia estrutural refere-se à área de engenharia civil que trata do estudo das causas, manifestações, implicações e modos de manifestações de falhas e dos métodos de desgaste das estruturas. As patologias em construções são os problemas mais importantes do comprometimento e da vida útil das edificações. O concreto é um dos materiais mais usados nos desenhos de estruturas feitas em concreto, as quais, no que lhe concerne, mediante o projeto e o implemento, delimitarão o potencial aparecimento de patologias, bem como da intensidade delas. A execução de estudos se faz essencial na busca da avaliação, caracterização e diagnóstico de possíveis danos nas construções, já que são fundamentais para o decurso de geração e uso das construções; possibilitam compreender ações eficazes e capazes de reduzir a ocorrência de anomalias e falhas, o que faz com que a qualidade geral das edificações melhore e otimiza a administração dos recursos. Uma nova área do conhecimento, que visa o estudo das manifestações patológicas possíveis de ocorrer no concreto armado é conhecida como patologia em concreto armado.

Averiguando-se essa conjuntura, ressalta-se o seguinte problema de pesquisa: quais são os principais métodos de recuperação estrutural em relação às patologias que ocorrem em concreto armado? Referente ao objetivo geral, aferiram-se as propriedades cruciais acerca da patologia em concreto armado e verificar os principais metodos de recuperação estrutural. Os objetivos específicos desse estudo são: descrição de aspectos conceituais sobre patologia em concreto armado; caracterização de questões relacionadas sobre a natureza do agravamento estrutural em concreto armado; avaliação de metodologias de recuperação estrutural no concreto armado. Esse estudo foi realizado por meio da metodologia de revisão bibliográfica 
narrativa (revisão de literatura), baseando-se em obras literárias, em artigos publicados em periódicos offline e também em artigos online reconhecidos no meio científico, onde buscou-se a verificação dos principais métodos de recuperação estrutural em relação às patologias que ocorrem em concreto armado.

\section{Metodologia}

O presente trabalho baseou-se em prestigiados autores da área e suas obras publicadas no campo da Engenharia Civil. No desenvolvimento dessa pesquisa utilizou-se o método da Revisão Bibliográfica Narrativa, uma revisão da literatura, a qual é uma análise ponderada e extensa da literatura disponível sobre um determinado assunto, utilizando livros, periódicos, jornais, artigos impressos e eletrônicos, de forma a reconhecer os autores que trataram sobre o tema anteriormente (Trentini \& Paim, 1999). O referencial teórico é essencial para fundamentar a proposta do estudo, assim como enriquecer a reflexão entre os autores mais relevantes no campo de pesquisa (Silva \& Trentini, 2002). Adortou-se, em conjunto com a referida proposta de revisão, uma abordagem qualitativa, visando uma pespectiva de resultados por meio da percepção e da análise, que tem por intuito descrever a complexidade do problema de pesquisa, concentrados na análise textual.

Os métodos qualitativos são aqueles nos quais é importante a interpretação por parte do pesquisador com suas opiniões sobre o fenômeno em estudo. Neles a coleta de dados muitas vezes ocorre por meio de entrevistas com questões abertas. Neste tipo de pesquisa algumas características, conforme Ludke e Andre,2013 como citado em Soares Pereira., et al. (2018, p.67).

Segundo Gil (2017), a revisão é uma reflexão sobre o material já produzido por outros autores, mas que se desenrola de forma imparcial tendo por base o entendimento do pesquisador e sua própria interpretação, de acordo com os objetivos préestabelecidos. No que concerne ao tipo de pesquisa, elegeu-se a pesquisa qualitativa, esta pode ser considerada um eficaz ponto de referência ao pesquisador, o qual é tratado como ponto principal de todo o processo em um estudo baseado na metodologia de Revisão Bibliográfica Narrativa - Revisão de Literatura (Cajueiro, 2012). Nesse ínterim, um procedimento metodológico guiado pela pesquisa qualitativa, a análise das informações coletadas tem o intuito de apresentar conclusões importantes e conexas, com base em um problema de pesquisa específico (Marconi \& Lakatos, 2017).

Assim, a metodologia de Revisão Bibliográfica Narrativa tem como principal objetivo o debate e a definição dos aspectos associados ao objeto de estudo, utilizando exclusivamente os conceitos observados em publicações de periódicos, livros, jornais, artigos, e demais meios de informação de grande relevância e impacto nomeio acadêmico (Lüdke \& André, 2013). A metodologia da Revisão Bibliográfica Narrativa tem a função de ser um trabalho amplo, delineadas para discutir o 'estado da arte' de um determinado assunto, sob uma perspectiva teórica ou contextual (Rother, 2007). Segundo Rother (2007), os textos usados na revisão narrativa constituem uma análise crítica, podendo contribuir no debate de tem éticas e atualizar o conhecimento em um curto espaço de tempo. De tal modo, a metodologia de Revisão Bibliográfica Narrativa adotada se mostra capaz de promover a devida discussão referente ao objeto de estudo definido no presente trabalho de pesquisa, buscando uma conclusão inovadora e o desenvolvimento de novos estudos (Marconi \& Lakatos, 2017).

\section{Resultados e Discussão}

\subsection{Patologia em Concreto Armado: Aspectos Conceituais}

De acordo com Botelho e Marchetti (2004), os romanos se mostraram inovadores na edificação de pontes de pedra na forma de arco - Figura 1. Quando não era possível a utilização de hastes retilíneas para transpor vãos maiores, os romanos adotaram uma estratégia: a utilização de arcos nos pontos onde individualmente as peças de pedra eram confeccionadas de modo a trabalhar apenas sob compressão. 
Figura 1 - Arcos requisitados por meio de compressão.

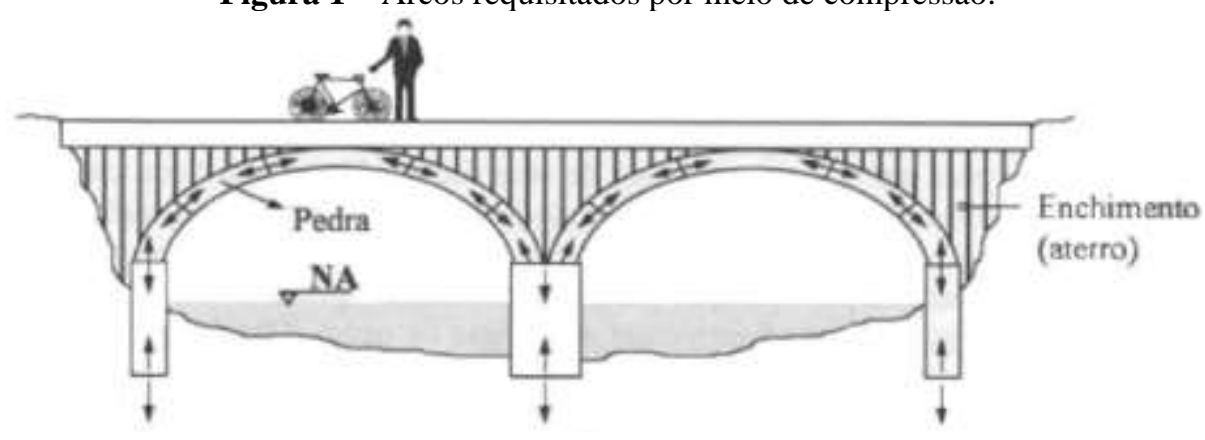

Fonte: Botelho e Marchetti (2004).

Em grandes vãos era necessária a utilização de arcos múltiplos, o que implicava em uma execução mais difícil, graças à tecnologia limitada da época. Apesar da descoberta e utilização do concreto, elemento resultante da fusão de cimento, pedra, areia e água, as adversidades permaneceram, já que o material resiste à ação da compressão em uma ordem dez vezes maior que à tração. Nessa perspectiva, a zona tracionada é suscetível à ocorrência de fissuras que podem ser desde um simples afetamento estético até mesmo condenar toda a construção à falência, conforme as extensões dessa. Dessa forma, passa-se a ter uma região solicitada somente pela tração, outra zona sobre a qual age somente a compressão, e uma terceira, considerada como uma linha neutra (Figura 2), onde não há compressão ou tração (Botelho \& Marchetti, 2004).

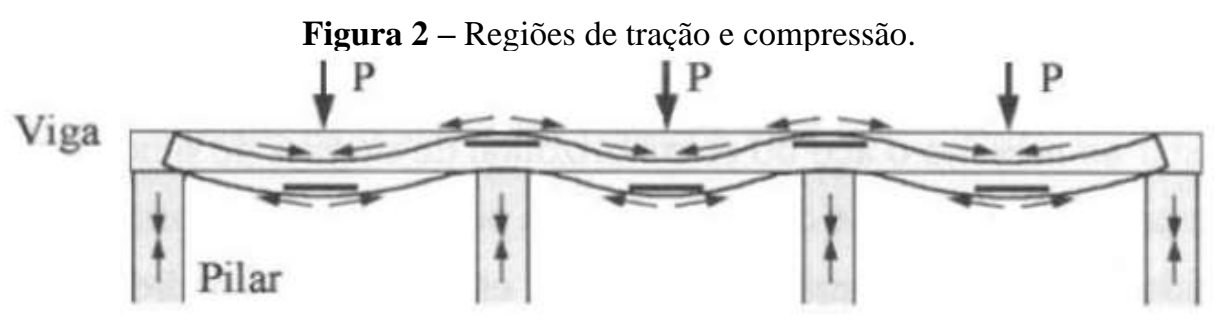

Fonte: Botelho e Marchetti (2004).

Para resolver a questão da baixa resistência à tração, são adicionadas barras de aço no segmento da seção onde a tração ocorre, e o concreto permanece como encarregado pelo suporte da compressão (Figura 3).

Figura 3 - Regiões de tração, compressão e área neutra com relação à estrutura.
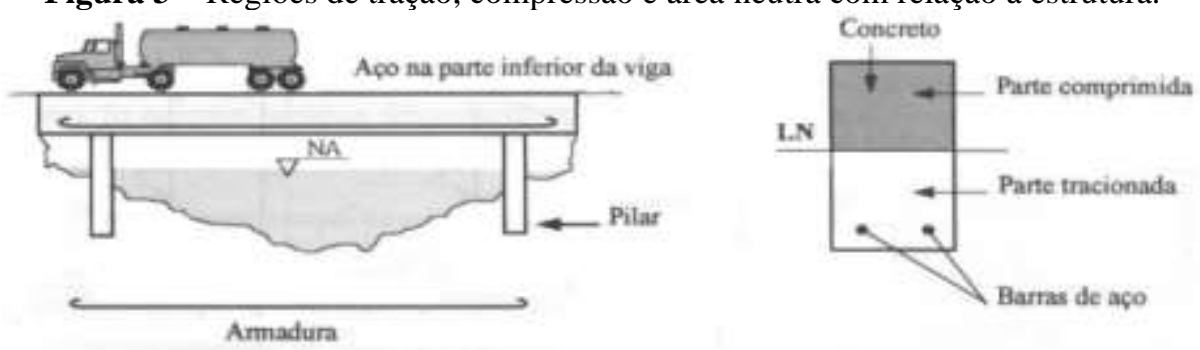

Fonte: Botelho e Marchetti (2004).

Assim, o concreto armado se consolidou como uma metodologia que atende às demandas da época. A contar da descoberta e utilização do concreto armado, bem como dos benefícios trazidos por este quando comparado às restantes metodologias e insumos da época, desencadeou-se uma progressiva e crescente utilização deste material. Ao lado da utilização do concreto armado, vieram as manifestações patológicas que este está sujeito, tanto pelo descuido e má utilização como pela mão-de-obra não qualificada em edificações ou mesmo a ignorância no emprego correto deste material (Trindade, 2015). 
A patologia do concreto armado é o ramo da ciência que lida com as aparições, mecanismos, motivos e geradores dos distúrbios patológicos ocorridos nas construções de estruturas feitas de concreto armado. Helene (1992) ressalta que ao se tratar de uma determinada falha, existem inúmeras possiblidades de agentes causais, tais danos podem ser responsáveis por pequenos desconfortos para os que farão uso do objetivo fim da construção, como a título de amostra pequenas infiltrações, ou inclusive enormes problemas que comprometerão a estrutura e culminará no colapso.

Frequentemente, em situações catastróficas, como prédios indo à ruína por não obedecerem à uma origem única, mas a diversas, que em conjunto são responsáveis por levar toda a estrutura a colapsar. Infelizmente, pode ser comum se deparar com estruturas onde um enorme desacerto foi permitido em uma das diversas fases, e assim mesmo não representam grandes danos consequentes. Porém, podem ser encontradas estruturas com grandes danos responsáveis pela redução da longevidade e resistência mecânica, causadas por desacertos ou fracassos de menor calibre, mas que quando agem de forma conjunta, seus efeitos ocorrem em sinergia, trazendo graves consequências (Cánovas, 1988).

Normalmente, falhas originadas nas etapas onde os quatro fatores, citados anteriormente estão envolvidos, apresentarão como decorrência falhas patológicas com soluções mais difíceis e de maior custo de recobramento do que distúrbios patológicos originados nas demais etapas posteriores. Souza e Ripper (1998) avultam que, normalmente, os impedimentos e o custo de recobramento de uma construção com falhas originadas de erros na elaboração do projeto, seriam proporcionais ao tempo ocorrido desde a ocorrência da falha, isto é, os erros datados do princípio da elaboração e continuados nas etapas conseguintes, tendem a ser responsáveis por prejuízos maiores. Erros preliminares, na fase de estudo, poderiam levar a soluções mais trabalhosas e complexas, quando comparados a erros ocorridos nas fases do anteprojeto.

Segundo Marcelli (2007) os erros de projetos estruturais podem ocorrer, porém seria bastante improvável que um escritório de engenharia possa ter sido responsável por diversos empreendimentos estruturais na ausência de erros em algum dos projetos desenvolvidos. $\mathrm{Na}$ imensa totalidade dos casos, os erros cometidos são percebidos e corrigidos rapidamente, ou ainda não seriam importantes o suficiente para serem percebidos.

\subsection{Natureza do Agravamento Estrutural em Concreto Armado}

Os motivos causais das manifestações patológicas podem ser de origens distintas, desde um erro humano no projeto ou na sua execução, até dificuldades com a conformação químico-física de componentes de materiais específicos, ou mesmo pela obra de origens agressoras do concreto ou armaduras. Souza e Ripper (1998) apontam que os motivos considerados intrínsecos podem ser definidas como as causas nas quais os métodos de deterioração das estruturas são inseparáveis a estes, isto é, causas advindas dos próprios materiais e suas peças estruturais, ocorridas ao longo do prazo de implemento ou de utilização, ou por erro humano, ou por circunstâncias inerentes ao material concreto, e inclusive pela ação de fatores externos, como imprevistos.

Em relação às falhas cometidas pelos profissionais encarregados pela construção, destaca-se o fato de que os erros construtivos e os erros de concepção de projeto podem ser causados por falha humana na grande maioria dos casos, principalmente pela qualidade questionável da mão-de-obra contratada. Algumas das falhas humanas mais comuns como causas de patologias em edificações são as falhas de execução, as concretagens ineficientes, a utilização de escoras e configurações inadequadas, a utilização de armaduras insuficientes, a utilização errônea de materiais de construção e a não observância do controle de qualidade (Trindade, 2015).

Um outro elemento capaz de responder por manifestações patológicas é o adensamento, tal processo tem a função de retirar ou diminuir ao extremo os espaços vazios no concreto, de forma a permitir que este tenha uma máxima resistência física e possibilite um melhor acomodamento do concreto nas formas e entre as armaduras presentes. No entanto, por ocasião do adensamento ser demasiado, haverá a distribuição da mistura, evoluindo para uma heterogeneidade da resistência mecânica da estrutura. Tanto o lançamento como o adensamento são processos quase simultâneos na obra, e a eficiência na execução de 
ambos é diretamente associada à resistência, à impermeabilidade e à resistência do concreto endurecido (Neville \& Brooks, 2013).

Consoante Trindade (2015), a cura do concreto permanece como um processo merecedor de especial atenção. Tal processo pode ser efetivado de diversas formas como o banho de formas se adotadas colunas, a irrigação das superfícies, a cobertura das superfícies com materiais que permitam a manutenção da umidade desejada, o uso de películas de cura a vapor, entre outros. A técnica de cura consiste em reduzir a evaporação da água na ausência das reações de hidratação do cimento, por meio do controle da umidade do local a ser concretado. Por ocasião de não haver uma correta realização deste processo, a estrutura de concreto armado estará passível de sofrer danos.

Segundo Thomaz (1989), um controle de qualidade ineficiente para estruturas de concreto armado é um dos fatores mais relevantes para o episódio de patologias. Materiais como o aço e o concreto são responsáveis pela durabilidade e resistência dos componentes da estrutura, e justamente por isso necessitam de um padrão de qualidade bastante restrito, desde a produção até a execução de uma determinada estrutura. Uma das questões que mais importam para a redução das chances de aparecimento de degradação precoce em estruturas, é a contratação de um engenheiro tecnologista, disponível durante toda a execução da obra, sua assistência posterior, este profissional deve obedecer às normas, no geral, mas maiormente no que faz referência à constituição e manufatura do concreto.

Verifica-se, dessa maneira, que um controle eficiente sobre a natureza dos materiais que serão usados em uma construção passa a ser um dos fatores preponderantes para a redução da probabilidade de desgaste precoce em estruturas, e com isso a prevenir prejuízos futuros, tanto materiais quanto pessoais.

\subsection{Métodos de Restauração Estrutural do Concreto Armado}

Segundo Trindade (2015) a recuperação ou o reforço de estruturas de concreto são serviços dependentes de análise minuciosa dos fatores causais que os produziram, bem como da pesquisa, em detalhe, dos efeitos consequentes. A partir destas definições, o autor parte para a escolha do método mais eficaz, incluindo a seleção cuidadosa dos materiais e equipamentos a serem utilizados, e para a mão-de-obra para a execução do serviço.

Azevedo (2011) destaca que os serviços de reforço de estruturas avariadas requerem uma elaboração prévia de cálculo estrutural, não importando se o serviço deriva da necessidade de mudança da função principal da estrutura ou se é oriundo de um desgaste sofrido pela estrutura, em ambas as situações o reforço faz parte dos trabalhos de recuperação.

O cálculo permite estabelecer quais seriam os critérios necessários para a instauração de determinados agentes, a saber a definição exata das peças estruturais necessárias para proceder o reforço, bem como a extensão da intervenção, e para as outras estruturas onde apenas a recuperação será suficiente. Se faz mister destacar a reconstituição das características geométricas, de resistência e de desempenho originalmente programadas; a afirmação da capacidade de resistência residual da estrutura, ou peça estrutural, e, assim, a definição do tipo, severidade e dimensão do reforço que se faz necessário; a indicação da adoção, ou não, de serviços de escoramento durante a execução dos trabalhos; a análise do status de segurança da estrutura, no todo e em suas partes, prévia, durante e após o serviço de reforço; a seleção do método a ser utilizado; a definição das etapas necessárias e dos volumes reais de trabalho a ser realizado, ou seja, a definição do gasto real envolvido na empreitada, juntamente com os elementos da inspeção técnica efetuada (Gonçalves, 2015).

Souza \& Ripper (1998) destaca que o custo final de serviços de recuperação ou reforço em estruturas de concreto pode ser considerado como uma função direta do recurso adotado para a andamento desta, devendo ser considerados os cálculos, as técnicas, as especificações dos materiais e dos trabalhos secundários, como por exemplo os escoramentos e os andaimes, estes, por diversas ocasiões, são condicionantes para a análise da própria viabilidade financeira da obra. O projetista tem a obrigação de, junto ao proprietário, esclarecer sobre as possíveis hipóteses e opções acerca dos custos de execução e seu resultado final, 
garantias a serem alcançadas em cada situação, bem como a previsão de custos futuros com a manutenção, isto é, avaliar os diferentes cenários e selecionar, utilizando por base estes elementos, da vida útil renovada da estrutura. Apenas após esta análise, o proprietário poderá ser capaz de tomar a decisão, auxiliado pelo profissional especialista na questão, sobre a execução dos trabalhos de reforço e /ou recuperação; ou ainda, pela decisão de não intervir na estrutura, ou em casos mais graves, pela demolição e reconstrução, total ou da parte danificada da estrutura (Trindade, 2015).

Marcelli (2007) evidencia que as recuperações e os reforços estruturais sobre estruturas de concreto armado devem obedecer a uma criteriosa conduta durante a preparação e a limpeza do substrato, estes procedimentos iniciais são obrigatórios previamente à execução do reforço ou da restauração. De nada resulta a utilização de sistemas e materiais adequados sem a preparação suficiente do substrato, tal necessidade influencia o sucesso decorrente do serviço, de forma a comprometer substancialmente a própria restauração ou o reforço. A primeira etapa deve ser a preparação do substrato sobre o qual se dará o reforço ou restauração, podendo ser realizado de várias formas, de acordo com as condições locais, a natureza e a dimensão dos serviços necessários. A higienização da superfície também é um procedimento que deve ser adimplido depois de preparar o substrato, imediatamente anterior à aplicação de produtos utilizados para a restauração ou reforço.

A utilização da técnica de polimento, necessária nos casos de ser a superfície de concreto bastante áspera, normalmente consequência de uma execução imprópria da estrutura, também derivada do desgaste esperado pelo uso e envelhecimento, de dosagens inadequadas de concreto, do uso de formas ásperas ou rústicas, ou ainda pela aplicação de vibração inadequada. Tal técnica é útil para diminuir a aspereza superficial do concreto, fazendo com que este fique liso novamente, sem a presença de resíduos desprendidos, utilizando para tanto equipamentos mecânicos, como, por exemplo, lixadeiras portáteis ou máquinas de polimento mais pesadas, necessárias nos casos em que a área a ser trabalhada é muito extensa (Souza, 2006). Para o manuseio dos equipamentos de polimento se faz necessária mão-de-obra especializada, assim como a cautela em relação à produção de resíduos, tanto para garantir a proteção do meio ambiente como a dos trabalhadores, já que este tratamento gera uma alta produção de ruídos sonoros e dispersa grandes quantidades de pó residual para o ambiente (Gonçalves, 2015).

A lavagem por meio de soluções ácidas auxilia na remoção das imperfeições que apenas o uso da água não é capaz de retirar. Esta lavagem é capaz de retirar vestígios de tinta, ferrugem, graxa, carbonatos, resíduos e manchas de cimento, por exemplo, o método não deve ser utilizado em casos onde a espessura de cobrimento da armadura for reduzida, ou nos casos de o local danificado esteja muito próximo às juntas de dilatação, já que existe o risco dos produtos entrarem em contato e penetrarem nessas juntas, isto é, deve haver o cuidado de evitar a penetração das soluções em locais onde não há certeza de sua remoção completa. Assim, neste último caso recomenda-se o uso de soluções alcalinas (Souza, 2006).

A limpeza com o auxílio de substâncias alcalinas segue o mesmo procedimento utilizado para as soluções ácidas, no que tange à lavagem inicial e aplicação da solução. No entanto, uma diferenciação que deve ser citada é relativa às precauções a serem tomados no uso destas substâncias. A utilização de tal classe de solução em áreas de concreto com agregados reativos, poderá ocasionar uma reação denominada álcalis-agregado, causada pelo contato entre ambos e capaz de gerar uma reação expansiva, por meio da liberação de sólidos em meio confinado (Souza \& Ripper, 1998).

O método de aplicação por meio de jatos d'água e de areia pode remover a camada degradada de concreto, a utilização de jatos d'água fria potável, frequentemente associada ao uso de jatos de areia, de forma alternada ou usando a mistura de ambos do mesmo modo que no concreto planejado por via seca. Quando da utilização do jato de areia se faz necessária a limpeza da mesma, a areia deve estar completamente seca e sem a presença de matéria orgânica, e esta deve ser descartada após o uso. A mangueira utilizada pode ser mantida, desde que a granulometria da areia esteja adequada ao calibre da mangueira, não permitindo entupimentos ou o polimento da superfície a ser recuperada (Azevedo, 2011).

Consoante Azevedo (2011), a utilização de jatos de água aquecida combinada a removedores biodegradáveis é uma opção para a remoção de resíduos muito gordurosos ou manchas bastante impregnadas em superfícies, porém a aplicação 
deverá ser realizada por operadores experientes, além da obrigatoriedade de utilização de EPI - Equipamento de Proteção Individual adequado. Frequentemente, utiliza-se um equipamento de alta pressão, do tipo lava-jato, caso seja possível, podem ser utilizadas algumas máquinas de projetar concreto de forma a reduzir o número de equipamentos alocados para a obra.

O jato de ar comprimido pode ser uma ferramenta complementar para a limpeza, nos casos onde os jatos de água ou areia não forem suficientes. A função do jato de ar comprimido é a de promover a retirada de partículas em cavidades, a direção do sopro deve ser do interior para o exterior, e deve-se proceder à secagem das superfícies ou de fissuras previamente à injeção das mesmas (Souza, 2006).

Gonçalves (2015) defende a utilização não como jato, mas como aspiração, essencialmente na limpeza de orifícios profundos, tais como aqueles presentes em ancoragem de barras de armaduras. Os principais cuidados de uso fazem referência ao uso de filtros de ar e óleo no equipamento compressor, a fim de evitar o refluxo de óleo.

Em determinados casos, o jato de limalha de aço pode ser uma possibilidade viável como substituta ao jato de areia. O equipamento tem seu funcionamento baseado nos mesmos princípios fundamentais de outros jatos, porém apresenta algumas características específicas. A limalha de aço é mais abrasiva que outros materiais e, por isso, é desaconselhável para utilização em armaduras expostas, com indícios de corrosão ou com diâmetros reduzidos. Nesse seguimento, o equipamento é menos poluente, quando comparado aos demais, além disso o método apresenta uma excelente eficiência para áreas extensas, sem a necessidade do uso de água. $\mathrm{O}$ jato pode quebrar a superfície de concreto menos resistente, além de permitir a abertura imediata dos poros, elevando a aderência do material de recuperação (Souza, 2006).

O reparo com o uso do graute parece ser utilizado frequentemente quando é necessário desformar rapidamente o local que foi reparado, para a posterior utilização da estrutura. Como a alta resistência do graute é atingida muito rapidamente, as formas são retiradas em períodos de até 24 horas após executado (Souza \& Ripper, 1998). Este produto apresenta boa fluidez, compacidade, uniformidade, além de não ser retrátil, e ser auto adensável, com cura umedecida por um período de tempo de três dias (Marcelli, 2007). Os grautes podem ser classificados como minerais, quando formulados a base de cimento ou como grautes poliméricos ou orgânicos, quando formulados à base de resina (Sanabria \& Helene, 2000).

Entre as vantagens do tratamento com concreto projetado, pode ser citada a não-necessidade da confecção de formas. No entanto, o custo elevado e a perda considerável de material durante o procedimento fazem com que este não seja viável para áreas pequenas. Quando apropriadamente aplicado, o concreto projetado é um material adequado estruturalmente, e de boa durabilidade, com excelente aderência a outros concretos, aço, alvenaria e demais materiais. Nesse sentido, as propriedades favoráveis da técnica são proporcionalmente dependentes de um planejamento adequado, de supervisão constante, da contratação de um operador habilitado e experiente, bem como da atenção contínua durante sua aplicação (Azevedo, 2011). Bezerra (1998) destaca que não é adequada a projeção de espessuras extensas de uma única vez, sendo recomendado a varrição da superfície, elevando-se progressivamente a espessura da concretagem, que deve ser de até 50mm.

Uma porção do concretado projetado é passível de reflexão quando entra em contato com a superfície a ser reparada, conforme citado anteriormente. Na fase inicial da execução do concreto projetado esse risco parece ser ainda mais relevante, reduzindo o concreto aderido à base. Em hipótese alguma, deve ser reutilizado o material refletido em outros jateamentos, uma vez que existe o risco de alteração da granulometria, da incidência de impurezas e de hidratação do cimento (Souza \& Ripper, 1998).

\section{Considerações Finais}

Com a presente pesquisa, permitiu-se uma análise acerca das patologias do concreto armado, isto é, mediante a realização de um levantamento completo das manifestações patológicas mais importantes no prejuízo de estruturas, foi capaz de apontar os principais sintomas, suas causas, mecanismos e consequências futuras destas nas edificações atingidas. 
Conforme evidenciado no decorrer do trabalho, inúmeras podem ser as razões e as origens responsáveis pelos problemas patológicos de uma estrutura, estas poderiam ser desencadeadas em diversas ocasiões, como nas etapas de planejamento, execução e uso de todos os componentes abrangidos.

Dentre as diversas causas a serem arroladas, encontram-se as dificuldades da constituição química dos materiais escolhidos; os fenômenos naturais, como a sazonalidade; os erros humanos de projeto e de execução, seja por negligência ou por qualidade insuficiente dos materiais elegidos, até mesmo a probabilidade de agressões biológicas e atuação de agentes atacantes às armações e ao próprio concreto. O presente trabalho também enfatizou uma sequência de terapias capazes de recuperar e reforçar as estruturas de concreto armado que tenham sido acometidas por problemas patológicos. É notório que embora novas tecnologias estejam disponíveis para a recuperação de estruturas afetadas, todas elas trazem desvantagens e dificuldades que ainda não tem sua resolução satisfatória.

As dificuldades que potencialmente atingem as estruturas são diversos e numerosos, e poderiam ser evitados pela adoção de cuidados mais rigorosos na confecção de projetos, na especificação e escolha dos materiais utilizados, no uso responsável da estrutura e de sua manutenção preventiva, tais cuidados poderiam, facilmente, reduzir, atenuar ou até extinguir a necessidade de sistemas de recuperação ou reparos de estruturas ameaçadas. Com efeito, é possível verificar que a escolha adequada do método, a ser desenvolvido na recuperação estrutural, poderá garantir o sucesso da empreitada, e que uma escolha infeliz ou inadequada poderá ser capaz de instabilizar ou até colapsar o problema estrutural.

O diagnóstico, capaz de identificar e classificar o acontecimento ou a probabilidade de episódio de manifestações patológicas é uma das condições mais fundamentais a serem adotadas na conduta adequada frente a anomalias em edificações. No entanto, é prudente questionar se a escolha e adoção de uma única técnica de inspeção e diagnóstico seria a mais indicada, já que para a construção de uma edificação se faz necessária a aplicação de diversos fatores, construtivos e executivos, bem como das diversas e dinâmicas circunstâncias inerentes à cada obra. Embora sejam inegáveis as melhorias dos métodos e abordagens construtivas, o emprego da compatibilidade de projetos e a especialização da mão-de-obra, o surgimento das manifestações patológicas nas edificações poderão ser oriundos de diversos outros motivos, assim, cabe ressaltar que a implementação de programas eficientes de inspeção e manutenção constantes poderão assegurar e garantir a longevidade das edificações.

Cabe destacar, como conclusão desta pesquisa, que permanece a necessidade pela busca da qualidade para a construção civil, bem como em outros segmentos da engenharia civil. Se faz importante compreender que para uma estrutura de concreto armado atingir um bom nível de desempenho, sem a ocorrência de manifestações patológicas, a totalidade das esferas envolvidas deverá estar em perfeita sintonia, estas vão desde a mão-de-obra para a execução do projeto; seus projetistas; os materiais a serem utilizados; a compreensão e o entendimento do solo e do ambiente onde a obra será executada; enfim, todos os elementos deverão encontrar a harmonia de excelência. $\mathrm{O}$ fato de existir um excelente quadro de recursos humanos no campo do implemento não afasta ou amortiza a obrigação de os insumos usados terem elevada qualidade e de proveniência garantida. A fim de afastar a possibilidade de surgimento de dificuldades patológicas, todas as questões envolvidas devem estar em sintonia e apresentarem um modelo menor de anuência, ou seja, nenhum deles deve estar em uma categoria demasiadamente inferior aos demais, sob pena de ocorrer uma falha em um setor, não compensada pela qualidade dos outros setores.

Assim, em síntese, o presente estudo analisou os principais métodos de recuperação estrutural em relação às patologias que ocorrem em concreto armado. Sugere-se, ainda, que outros estudos sejam desenvolvidos para discutir e fortalecer o tema da presente pesquisa, levando-se em consideração a evolução da sociedade e do mercado, bem como os principais autores da área de engenharia civil. 


\section{Referências}

Azevedo, M. T. (2011). Patologia das Estruturas de Concreto. Ibracon.

Bezerra, J. E. A. (1998). Estruturas de Concreto Armado: Patologia e Recuperação.

Botelho, M. H. C., \& Marchetti, O. (2004). Concreto armado eu te amo. Edgar Blucher.

Brasil. Lei no 10.406, de 10 de janeiro de 2002. (2020). Institui o Código Civil. http://www.planalto.gov.br/ccivil_03/LEIS/2002/L10406.htm.

Cajueiro, R. L. P. (2012) Manual para elaboração de trabalhos acadêmicos: guia prático do estudante. (3a ed.), Vozes. 112 p.

Cánovas, M. F. (1988). Patologia e Terapia do Concreto Armado. Trad. M. C. Marcondes; C. W. F. dos Santos; B. Cannabrava. 522 p. Pini.

Gil, A. C. (2017) Como elaborar projetos de pesquisa. (6a ed.), Atlas. 192 p.

Gonçalves, E. A. B. (2015). Estudo de Patologias e suas Causas nas Estruturas de Concreto Armado de Obras de Edificações. 2015.174 f. Monografia (Graduação em Engenharia Civil). UFRJ - Universidade Federal do Rio de Janeiro. Escola Politécnica. Rio de Janeiro: UFRJ.

Helene, P. R. L. (1992).Manual prático para reparo e reforço de estruturas de concreto. 119 p. Pini.

Lüdke, M., \& André, M. E. D. A. de. (2013). Pesquisa em educação: abordagens qualitativas. (2a ed.), EPU. 128 p.

Marcelli, M. (2007).Sinistros na construção civil: causas e soluções para danos e prejuízos em obras. Pini.

Marconi, M. de A., \& Lakatos, E. M. (2017). Metodologia do trabalho científico. (8a ed.), Atlas. 256 p.

Martins, G. A.., \& Pinto, R. L. (2001). Manual para elaboração de trabalhos acadêmicos. Atlas. 96 p.

Miotto, D. (2010). Estudo de Caso de Patologias Observadas em Edificação Escolar Estadual no Município de Pato Branco-PR. 63 f. Monografia (PósGraduação em Construção de Obras Públicas). UFPR - Universidade Federal do Paraná. Programa de Residência Técnica da Secretaria de Estado de Obras Públicas (SEOP). Curitiba: UFPR, 2010. https://acervod igital.ufpr.br/bitstream/han dle/188/34 353/MIOTTO,\%20DANIELA.pdf

Neville, A. M., \& Brooks, J. J. (2013). Tecnologia do Concreto. (2a ed.). Bookman.

Pereira, A. S. et al. (2018).Metodologia da pesquisa científica. UFSM. https://rep ositorio.ufsm.br/bitstream/handle/1/15824/Lic_Computacao_MetodologiaPesquisa-Cientifi ca.pdf?sequence $=1$.

Relvas, F. J. (2004). Curso de estruturas de concreto: projeto, execução e reparo. Reforço de peças de concreto armado, com chapas de aço dez.

Rother, E. T. (2007). Revisão sistemática x revisão narrativa. Acta Paulista de Enfermagem. 20(2), 5-6.

Sanabria, L. T., \& Helene, P. R. L. (2000). Contribuição ao estudo da resistência à corrosão de armaduras de aço inoxidável. Tese (Doutorado em Engenharia Civil). USP - Universidade de São Paulo. São Paulo: USP.

Silva, D. G. V., \& Trentini, M. (2002). Narrativas como técnica de pesquisa em enfermagem. Revista Latino-Americana de Enfermagem. 10(3).

Souza, E. A. da. (2006). Técnicas de recuperação e reforço de estruturas de concreto armado. 84 f. Monografia (Graduação em Engenharia Civil). Universidade Anhembi Morumbi. São Paulo: Universidade Anhembi Morumbi.

Souza, V. C., \& Ripper, T. (1998).Patologia, recuperação e reforço de estruturas de concreto. 255 p. Pini.

Takata L. T. (2009). Aspectos executivos e a qualidade de estruturas em concreto armado: Estudo de caso. 2009. Dissertação (Mestrado em Engenharia Civil). UFSCar - Universidade Federal de São Carlos. São Carlos: UFSCar.

Thomaz, E. (1989).Trincas em Edifícios: causas, prevenção e recuperação. Pini.

Trentini, M., \& Paim, Lygia. (1999). Pesquisa em enfermagem. Uma modalidade convergente-assistencial. Florianópolis: Editora da UFSC.168 p.

Trindade, D. dos S. da. (2015). Patologia em Estruturas de Concreto Armado. 88 f. Monografia (Graduação em Engenharia Civil). UFSM - Universidade Federal de Santa Maria. Centro De Tecnologia. Santa Maria: UFSM. 